\title{
Prevalence of childhood illness and mothers'/caregivers' care seeking behavior in Bahir Dar, Ethiopia: A descriptive community based cross sectional study
}

\author{
Worku Awoke \\ College of Medicine and Health Sciences, Bahir Dar University, Bahir Dar, Ethiopia; workuawo@yahoo.com \\ Received 8 January 2013; revised 25 February 2013; accepted 8 April 2013 \\ Copyright (C) 2013 Worku Awoke. This is an open access article distributed under the Creative Commons Attribution License, which \\ permits unrestricted use, distribution, and reproduction in any medium, provided the original work is properly cited.
}

\section{ABSTRACT}

Introduction: In Ethiopia, even though there are great achievements in decreasing infant and child mortality from year 2000 to 2011 , still children are suffering from diarrheal diseases, respiratory problems and malnutrition. This study was done to determine the prevalence of illnesses among under-five children and mothers'/caregivers' care seeking behavior for childhood illnesses in Bahir Dar, Ethiopia. Methods: A community based cross-sectional study was done on a sample of 415 mothers/caregivers from April 15 to May 15, 2011. Three kebeles (the smallest administrative unit) from Bahir Dar were selected randomly. The sample was proportionally distributed to the selected kebeles according to their population size. To be eligible to participate in the study, mothers had to live in households that had children under five years of age. These households were selected by systematic sampling method. Mothers/caregivers were interviewed in their homes using a structured questionnaire that had been pre-tested. The collected data were analyzed using a computer program of SPSS version 20.0. Result and Conclusions: The overall two weeks prevalence of childhood illness that had one or more symptoms of disease was 110 (26.5\%). The prevalence of the most commonly reported symptoms were diarrhea, fever, acute respiratory infection (ARI) and others $11.3 \%, 10 \%, 6.3 \%$ and $4.6 \%$ among children of under five years respectively. Eighty $(\mathbf{7 2 . 7 \%})$ of mothers sought treatment from health care facilities for sick children. The main reasons for not seeking treatment from health care facilities as reported by mothers/caregivers were, $53.3 \%$ Illness was not serious, $26.7 \%$ lack of money and $13.3 \%$ did not see any benefit for such childhood illness. Hence there is a need for designing a tailored health message for motherl caregivers about preventable childhood illness and treatment seeking by the local health extension workers and program planners.

Keywords: Care Seeking Behavior; Childhood Illness; Ethiopia

\section{INTRODUCTION}

Globally, despite a significant progress has been made in reducing mortality in children under five years of age, about 6.9 million children of under five years died in 2011. Children in Sub-Saharan Africa are about 16.5 times more likely to die before the age of five years than children in developed region [1,2].

Pneumonia and diarrhea are leading killers of the world's youngest children, accounting for 29 percent of deaths among children under 5 years of age in worldwide. Nearly 90 percent of deaths due to pneumonia and diarrhea occur in Sub-Saharan Africa and South Asia [3].

A better understanding of child health epidemiology could contribute to more effective approaches to saving children's lives [4]. Improving families' care seeking behavior could contribute significantly to reducing child mortality in developing countries. The World Health Organization estimates that seeking prompt and appropriate care could reduce child deaths due to acute respiratory infections by $20 \%$ [5]. Health-seeking behavior is a function not only of the availability of health facilities and 
other sources of healthcare but also motivation and ability of individuals to seek medical treatment [6].

In Ethiopia, even though there are great achievements in decreasing infant and child mortality from year 2000 to 2011, still large proportions of Ethiopian children are suffering from diarrheal diseases, respiratory problems and malnutrition [7-9]. An estimated 75 percent of health problems of Ethiopia are due to infectious and communicable diseases, which could be easily prevented or controlled by applying simple sanitary measures [10].

In response to the country's health problem the government introduces Health Extension Program (HEP). HEP was designed based on the concepts and principles of Primary Health Care, to improve the health status of families, with their full participations, using local technologies and the community's skills and wisdom [11]. However, few studies were conducted in Ethiopia with regard to care seeking behavior of mothers for childhood illness [12-15]. Detail information in the local setting was lacking. Findings from this study are intended to inform the local health extension workers and planners about the prevalence of illness among children under five years of age and care seeking behavior of mothers during child hood illness.

\section{METHODS}

\subsection{Study Design}

A community based cross-sectional study was done on a sample of 415 mothers/caregivers from April 15 to May 15, 2011. Three Kebeles (the smallest administrative unit) from Bahir Dar were selected randomly. The sample was proportionally distributed to the selected Kebeles according to their population size. To be eligible to participate in the study, mothers had to live in households that had children under five years of age. These households were selected by systematic sampling method. Mothers/caregivers were interviewed in their homes using a structured questionnaire that had been pre-tested. When there was more than one child of under five years in the household, mothers were asked about the last child. Respondents were not included in the survey if there were not at home up to three times when the interviewers went to the house.

\subsection{Sample Size Determination}

The sample size was determined by using single proportion formula. The following assumption were made, since there was no any study reporting the current population proportion $(\mathrm{P})$, assumed to be $50 \%(\mathrm{P}=50 \%)$, marginal error $(\mathrm{W})$ that will be tolerated in ether sides of the true proportion to be $5 \%$, and using $95 \%$ confidence level and adding $10 \%$ to compensate for non responses, bringing the final sample size to 422 mothers/caregivers of children of under five years of age.

\subsection{Data Collection}

A structured questionnaire was prepared according to the study objectives and the local situations of the study area with English language. The questionnaire was translated to Amharic and back translated to English. Discrepancies in the translation were resolved through mutual agreement in the research team. Pre-testing was conducted on $5 \%$ of sample size prior to the actual data collection process. Then a pretested structured questionnaire was used to collect data on socio-demographic characteristics, childhood illness and care seeking behavior of mothers/care givers of under five years of age. Data were analyzed using SPSS version 20.0.

\subsection{Operational Definitions}

1) Acute respiratory infection (ARI): all cases that had cough, problem on breathing and reported by mothers or care givers within two weeks preceding the survey.

2) Diarrhea: Three or more loose or watery stools per day, or blood in stool as perceived and reported by mothers or care givers within two weeks preceding the survey.

3) Fever: Increased body temperature or being hot body of the selected child as perceived and reported by mothers or care givers within two weeks preceding the survey.

4) Care seeking behavior: mothers/caregivers response for signs and symptoms of illnesses to reduce severity and complication after recognizing the child's illness.

\subsection{Limitations}

Data collections were based on mothers/caregivers responses using a structured and pretested questionnaire. And had limitations about the actual symptoms of illnesses as defined in health care setting and also had gaps with respect to the actual and reported care seeking behavior of mothers/caregivers for childhood illness.

\subsection{Ethical Considerations}

The research topic and methodology was approved by ethical clearance committee of College of Medicine and Health Sciences, Bahir Dar University. A written consent was sought from the Health Office of Bahir Dar City Administrations. At each level the aim of the study was explained for community leaders and heads of the households and informed oral consent was obtained. Additionally, during the data collection at each selected household the aim of the study were clearly explained for the heads of the households and for mothers/caregivers of children of under five years of age. Respondents were assured about the confidentiality of the information they provided 
as well as their right to withdraw at any time during data collection. Oral consent was obtained from all the study participants prior to data collection.

\section{RESULTS AND DISCUSSIONS}

\subsection{Socio-Demographic Characteristics of Mothers/Caregivers and the Selected under Five Children}

In this study, 415 mothers/caregivers were interviewed after fulfilling the inclusion criteria, resulting in an overall response rate of $98.34 \%$. Majority of study participants, $383(92.3 \%)$ were biological mothers of the selected child, and $403(97.1 \%)$ were from the Amhara ethnic groups. $303(73.0 \%)$ were in the age group of 20 to 35 years. 346 (83.4\%) were Orthodox Christians. 180 (43.4\%) were unable to read and write, $342(82.4 \%)$ were married, 275 $(66.3 \%)$ were from households having family less than or equal to five. With regard to the socio demographic characteristics of the youngest under five years of children, $218(52.5 \%)$ were female, $166(40.0 \%)$ were first by their birth orders, $365(88.0 \%)$ of the mothers were followed Antennal care services (ANC) during the pregnancy of the selected children and 149 (35.9\%) mothers delivered their youngest child at home (Table 1).

\subsection{Childhood Illness and Care Seeking Behavior of Mothers/Primary Care Givers}

Mothers/care givers were asked about the health status of the selected under five children in the past two weeks proceeding to this study. The overall two weeks prevalence of childhood illness that had one or more symptoms of disease was $110(26.5 \%)$. The prevalence of the most commonly reported symptoms were diarrhea, fever, acute respiratory infection (ARI) and others $11.3 \%, 10 \%, 6.3 \%$ and $4.6 \%$ among children of under five years respectively (Figure 1). When we compared this find with the findings from Ethiopian Demographic and Health Survey, prevalence of diarrhea and ARI was comparable with the national figure, however the two week prevalence fever was lower among children of under five years of age in Bahir Dar [9]. This might be due to low reporting of fever cases. Prevalence ARI were lower as compared with a research report from West Bengal which was reported as 56.8\%, $23.8 \%$ and $18.9 \%$ children suffered from ARI, fever and diarrhea respectively [16].

With regard to mothers'/caregivers' perceptions about the severity illness, 76 (69.1\%), 33 (30.0\%) and 1 (0.9\%) reported as mild, sever and life threatening respectively. Out of 110 children of under five years of age who had one or more symptoms, $51(46.4 \%)$ received home care at household level by mothers/caregivers (Table 2).
Table 1. Socio-demographic characteristics of mothers/caregivers and the selected youngest child, Bahir Dar, Ethiopia, 2011.

\begin{tabular}{|c|c|c|}
\hline Variables & Frequency (N) & Percent (\%) \\
\hline \multicolumn{3}{|l|}{ Primary caregiver } \\
\hline Mother & 383 & 92.3 \\
\hline Father & 11 & 2.7 \\
\hline Sister & 8 & 1.9 \\
\hline Others & 13 & 3.1 \\
\hline Total & 415 & 100 \\
\hline \multicolumn{3}{|l|}{ Ethnicity } \\
\hline Amhara & 403 & 97.1 \\
\hline Ormo & 7 & 1.7 \\
\hline Tigre & 4 & 1.0 \\
\hline Others & 1 & 0.2 \\
\hline Total & 415 & 100 \\
\hline \multicolumn{3}{|l|}{ Age } \\
\hline$<20$ years & 40 & 9.6 \\
\hline $20, \leq 35$ years & 303 & 73.0 \\
\hline Above 35 years & 72 & 17.3 \\
\hline Total & 415 & 100 \\
\hline \multicolumn{3}{|l|}{ Religion } \\
\hline Orthodox Christians & 346 & 83.4 \\
\hline Catholic Christians & 1 & 0.2 \\
\hline Protestants & 5 & 1.2 \\
\hline Muslim & 63 & 15.2 \\
\hline Total & 415 & 100 \\
\hline \multicolumn{3}{|l|}{ Literacy status } \\
\hline Unable to read and write & 180 & 43.4 \\
\hline Able to read and write & 235 & 56.6 \\
\hline Total & 415 & 100 \\
\hline \multicolumn{3}{|l|}{ Marital status } \\
\hline Married & 342 & 82.4 \\
\hline Single & 18 & 4.3 \\
\hline Divorced & 43 & 10.4 \\
\hline Widowed & 12 & 2.9 \\
\hline Total & 415 & 100 \\
\hline \multicolumn{3}{|l|}{ Family size } \\
\hline$\leq 5$ & 275 & 66.3 \\
\hline$>5$ & 140 & 33.7 \\
\hline Total & 415 & 100 \\
\hline \multicolumn{3}{|c|}{ Sex of the of the selected children } \\
\hline Male & 197 & 47.5 \\
\hline Female & 218 & 52.5 \\
\hline Total & 415 & 100 \\
\hline \multicolumn{3}{|c|}{ Birth order of the selected children } \\
\hline 1 st & 166 & 40.0 \\
\hline 2nd & 103 & 24.8 \\
\hline $3 \mathrm{rd}$ & 72 & 17.3 \\
\hline 4th and above & 74 & 17.8 \\
\hline Total & 415 & 100 \\
\hline \multicolumn{3}{|c|}{$\begin{array}{l}\text { ANC follow up during pregnancy } \\
\text { of the selected children }\end{array}$} \\
\hline Yes & 365 & 88.0 \\
\hline No & 50 & 12.0 \\
\hline Total & 415 & 100 \\
\hline \multicolumn{3}{|c|}{$\begin{array}{l}\text { Place of delivery of the selected } \\
\text { children }\end{array}$} \\
\hline Home & 149 & 35.9 \\
\hline Health institutions & 266 & 64.1 \\
\hline Total & 415 & 100 \\
\hline
\end{tabular}


During childhood illness mothers/caregivers sought treatment for $80(72.7 \%)$ from either governmental or private health care facilities found in Bahir Dar (Table 2).

Treatment seeking from health care facilities in Bahir Dar was lower as comparing a research report from other parts of Ethiopia on which $87.2 \%$ urban cases of under-

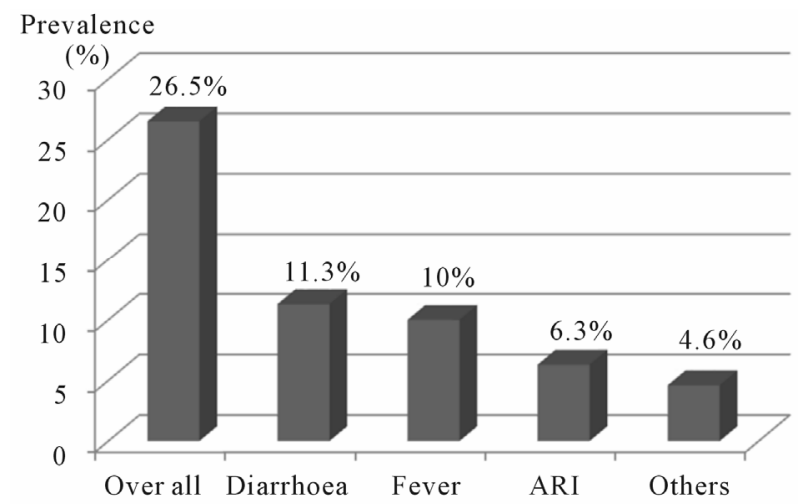

Figure 1. Two week prevalence of childhood illness among children of under five years, Bahir Dar, Ethiopia, 2011.

Table 2. Childhood illness and care seeking behavior of mothers/caregivers of under-five children, Bahir Dar, 2011.

\begin{tabular}{|c|c|c|}
\hline Variables & Frequency (N) & Percent (\%) \\
\hline \multicolumn{3}{|l|}{ Was the child sick } \\
\hline Yes & 110 & 26.5 \\
\hline No & 305 & 73.5 \\
\hline Total & 415 & 100 \\
\hline \multicolumn{3}{|l|}{ Perceived severity } \\
\hline Mild & 76 & 69.1 \\
\hline Sever & 33 & 30.0 \\
\hline Life threatening & 1 & 0.9 \\
\hline Total & 110 & 100 \\
\hline \multicolumn{3}{|c|}{$\begin{array}{l}\text { Was home care given during } \\
\text { child illness }\end{array}$} \\
\hline Yes & 51 & 46.4 \\
\hline No & 59 & 53.6 \\
\hline Total & 110 & 100 \\
\hline \multicolumn{3}{|c|}{$\begin{array}{c}\text { Treatment seeking from health } \\
\text { institution }\end{array}$} \\
\hline Yes & 80 & 72.7 \\
\hline No & 30 & 27.3 \\
\hline Total & 110 & 100 \\
\hline \multicolumn{3}{|c|}{$\begin{array}{c}\text { Main reason for not seeking } \\
\text { treatment }\end{array}$} \\
\hline Illness was not serious & 16 & 53.3 \\
\hline No money & 8 & 26.7 \\
\hline Did not see the benefit & 4 & 13.3 \\
\hline Others & 2 & 6.7 \\
\hline Total & 30 & 100 \\
\hline \multicolumn{3}{|c|}{$\begin{array}{c}\text { Decision maker in selecting place } \\
\text { of treatment }\end{array}$} \\
\hline Mother & 53 & 48.2 \\
\hline Father & 21 & 19.1 \\
\hline Both & 35 & 31.8 \\
\hline Grandmothers/fathers & 1 & 0.9 \\
\hline Total & 110 & 100 \\
\hline
\end{tabular}

five children were taken to health facilities [12]. In West Bengal, the overall treatment rate was above $93 \%$ and most of the children were treated in hospitals and health centre [16].

Treatments were not sought for $30(27.3 \%)$ of sick under-five children. Mothers'/caregivers' the main reasons for not seeking care from health facilities were 53.3\% illness was not serious, $26.7 \%$ lack of money and $13.3 \%$ did not believe the benefit care seeking from health facilities for such childhood illness (Table 2). This was consistent with reports from other studies about mothers' responses and practices were frequently influenced by their perception about severity of illness $[12,17]$

\section{CONCLUSION}

The two-week prevalence of diarrhea, fever and acute respiratory infection (ARI) were still higher in children of under five years in Bahir Dar. Treatment seeking for childhood illness was low. Perception of mothers about the childhood illness was not satisfactory. Illness was not serious, lack of money and mothers'/caregivers' thought about the ability of health care facilities in treating childhood illness were among the factors influencing treatment seeking of mothers/caregivers. Hence, there is a need for designing a tailored health message for mothers/caregivers about preventable childhood illness and treatment seeking by the local health extension workers and program planners.

\section{ACKNOWLEDGEMENTS}

I would like to thank Bahir Dar University for the material and finical support. I am also grateful for the cooperation of the study participants and grateful the district health office of Bahir Dar for their kind assistance when preparing the proposal and in the final data collection.

\section{REFERENCES}

[1] WHO (2012) Millennium Development Goals (MDGs). http://www.who.int/mediacentre/factsheets/fs290/en/inde x.html

[2] WHO (2012) Children: Reducing mortality. http://www.who.int/mediacentre/factsheets/fs178/en/inde $\underline{\mathrm{x} . h \mathrm{hml}}$

[3] UNICEF (2012) Pneumonia and diarrhea-Tackling the deadliest diseases for the world's poorest children. United Nations Children's Fund (UNICEF), New York.

[4] Black, R.E., Morris, S.S. and Bryce, J. (2003) Child survival I, where and why are 10 million children dying every year. The Lancet, 361, 2226-2234.

[5] World Health Organization (1991) Technical bases for the WHO recommendations on the management of pneumonia in children at first level health facilities. WHO, Geneva.

[6] Teerawichitchainan, B. and Phillips, J.F. (2007) Ethnic 
differentials in parental health seeking for childhood illness in Vietnam: Working paper No. 3. Population Council, New York.

[7] Central Statistical Authority [Ethiopia] and ORC Macro (2001) Ethiopia Demographic and Health Survey (EDHS) 2000. Central Statistical Authority and ORC Macro, Addis Ababa and Calverton.

[8] Central Statistical Agency [Ethiopia] and ORC Macro (2006) Ethiopia Demographic and Health Survey (EDHS) 2005. Central Statistical Agency and ORC Macro, Addis Ababa and Calverton.

[9] Central Statistical Agency [Ethiopia] and ICF International (2012) Ethiopia Demographic and Health Survey (EHHS) 2011. Central Statistical Agency and ICF International, Addis Ababa and Calverton.

[10] Ministry of Health (MOH) (1998 EC) Health and health related indicators 2005/6. Planning and Programming Department, Addis Ababa.

[11] Ethiopia Federal Ministry of Health (2007) Health Extension Program in Ethiopia. Health Extension and Education Centre, Addis Ababa.

[12] Assefa, T., Belachew, T., Tegegn, A. and Deribew, A. (2008) Mothers' health care seeking behavior for childhood illnesses in Derra District, Northshoa Zone, Oromia
Regional State, Ethiopia. Ethiopian Journal of Health Sciences, 18, 87-94.

[13] Warren, C. (2010) Care of the newborn: Community perceptions and health seeking behavior. Ethiopian Journal of Health Development, 24, 110-114.

[14] Tessema, F., Asefa, M. and Ayele, F. (2002) Mothers' health services utilization and health care seeking behaviour during infant rearing: A longitudinal community based study, south-west Ethiopia. Ethiopian Journal of Health Development, 16, 51-58.

[15] Getahun, A., Deribe, K. and Deribew, A. (2010) Determinants of delay in malaria treatment-seeking behaviour for under-five children in south-west Ethiopia: A case control study. Malaria Journal, 9, 320. doi:10.1186/1475-2875-9-320

[16] Dey, I. and Chaudhuri, R.N. (2012) A study on morbidity pattern and health seeking behaviour among under-five children in a rural area of West Bengal. International Journal of Medicine and Public Health, 2, 15-17.

[17] Grace, M., Mark, O., Ruth, K., et al. (2005) Mother's health seeking behavior during child illness in a rural western Kenya community. African Health Sciences, 5, 322-327. 